\title{
Snapshot view of emergency neurosurgical head injury care in Great Britain and Ireland
}

\author{
Darach W Crimmins, James D Palmer
}

University

Department of

Neurosurgery,

Institute of Neurology,

National Hospital for

Neurology and

Neurosurgery, Queen

Square, London

WC1N 3BG, UK

D W Crimmins

J D Palmer

Correspondence to:

Mr James D Palmer,

Department of

Neurosurgery, Derriford

Hospital, Plymouth PL6

8DH, UK

email james.palmer@,

phnt.swest.nhs.uk

Received 13 November 1999

and in revised form

28 July 1999

Accepted 13 August 1999

\begin{abstract}
Objectives-To study the availability of neurosurgical intensive care for the traumatically brain injured in all 36 neurosurgical centres in the United Kingdom and Ireland receiving head injuries, the response times to referral, and the advice given to the referring hospitals.

Methods-Telephone survey of receiving neurosurgeons regarding their bed status and their advice on three hypothetical case scenarios. Outcome measures included response times for an acute head injury to be accepted to a neurosurgical centre; the intensive care bed status; variations in advice given to the referring hospitals with regard to ventilation, use of mannitol, steroids, anticonvulsants, and antibiotics.

Results-There were 43 neurosurgical intensive care beds available for an overall estimated population of $63.6 \mathrm{mil}-$ lion. There were 1.8 beds available/ million of the population for non-
\end{abstract}

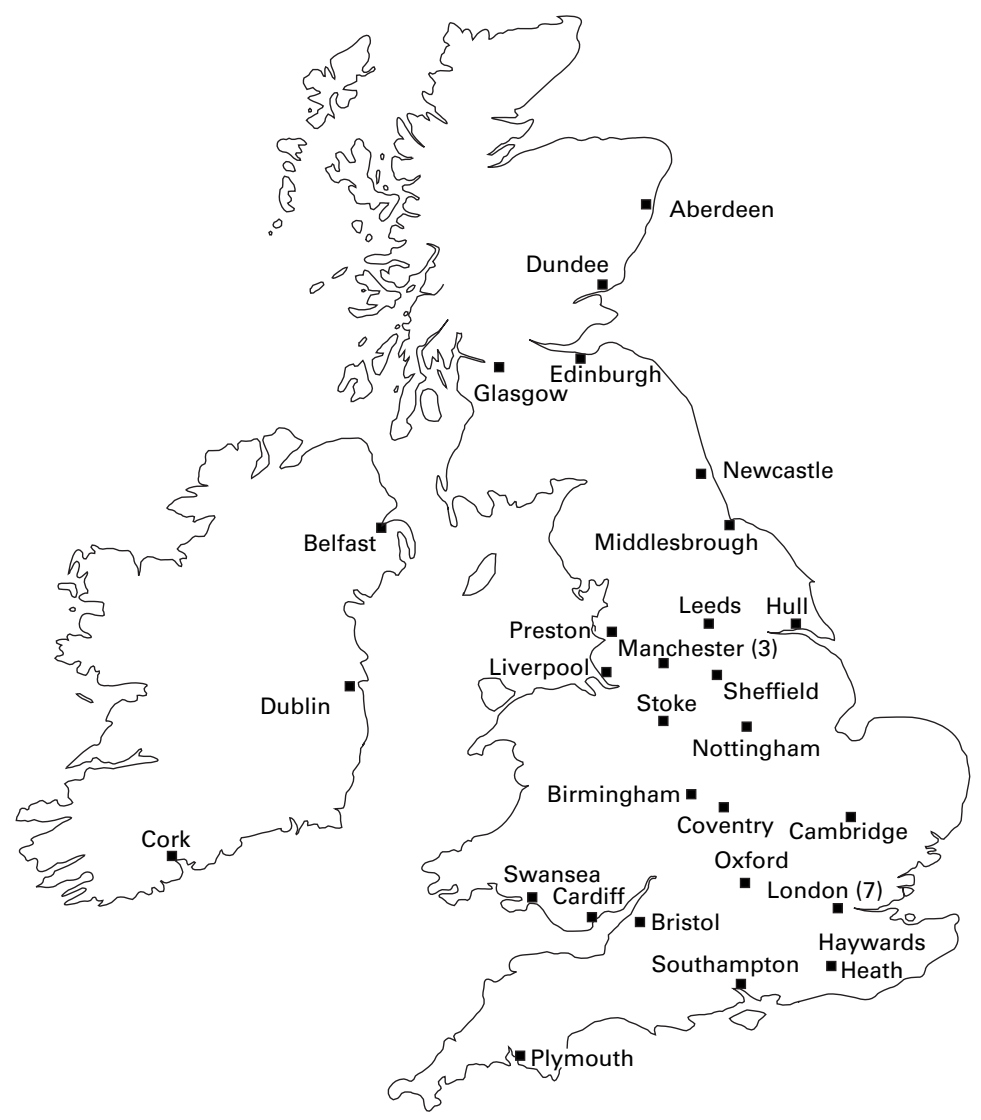

Neurosurgical intensive care units in the United Kingdom and Ireland. Note that there are three units in Manchester and seven in London ventilated patients, 0.64 beds available/ million for ventilated patients, and 0.55 beds available/million for ventilated paediatric patients. London had a shortage of beds with 0.19 adult beds for ventilation/ million north of the Thames and 0.14 adult beds for ventilation/million south of the Thames. The median response time for a patient with an extradural haematoma to be accepted for transfer was 6 minutes and $89 \%$ of such a referral was accepted within 30 minutes. Clinically significant delays in receiving referrals (over 30 minutes) occurred in four units. Practices regarding the use of hyperventilation, mannitol, anticonvulsants, and antibiotics showed little conformity and in some cases were against the available evidence and advice given by published guidelines.

Conclusions-There is a severe shortage of available emergency neurosurgical beds especially in the south east of England. The lack of immediately available neurosurgical intensive care beds results in delays of transfer that could adversely affect the outcome of surgery for traumatic intracranial haematoma. Advice given to the referring units by the receiving doctors is very variable. (F Neurol Neurosurg Psychiatry 2000;68:8-13)

Keywords: head injury; transfer; intensive care unit; resources for healthcare

A planning committee of the Society of British Neurological Surgeons (SBNS), after the second world war, ${ }^{1}$ recommended confining neurosurgeons to regional centres (at that time only 14 in the United Kingdom and Ireland) to where severe head injuries would be referred from outlying district general hospitals (DGHs), to expand services in the existing neurosurgical units, and that additional centres be created in regions where services were inadequate. There are now 36 neurosurgical units.

The number of patients needing treatment for head injury in a specialised unit has been increasing since 1945. The population of the United Kingdom and Ireland has increased from 53 million in 1946 to 63.6 million in $1994 .^{23}$ Neurosurgical practice has changed since the 1940 s to include the management of patients with closed head injury without an intracranial mass lesion demanding the specialised resources of a neurosurgical intensive care unit. $^{4-6}$

The objective of this study was to evaluate the availability and accessibility of acute 
neurosurgical beds for head injury care in Great Britain and Ireland and the variations in advice given to referring hospitals by the on call neurosurgeon.

\section{Methods}

A telephone survey of all 36 neurosurgical units receiving acute heads injuries in the United Kingdom and Ireland was undertaken on Tuesday 2 September 1997. This date was chosen because it was the day before the biannual meeting of the Society of British Neurological Surgeons and elective work was likely to be at a minimum while still having a full com-

\section{Clinical scenarios presented over the} phone to the receiving neurosurgeon

PATIENT 1 (EXTRADURAL HAEMATOMA)

A 30 year old man with no helmet fell off his bike, sustaining a head injury. He lost consciousness for 2-3 minutes. On arrival to the hospital, he was eye opening to speech, oriented, and obeying commands. He had a headache and vomited twice. Examination showed a right parietal boggy swelling with a 7 $\mathrm{cm}$ laceration but no other injuries. Soon afterwards, he started deteriorating, eye opening to pain, muttering incomprehensible sounds, and localising. His pupils were equal and reacting. His pulse rate was 76 per minute, his blood pressure $140 / 80 \mathrm{~mm} \mathrm{Hg}$, and his respiratory rate $20 / \mathrm{min}$. Chest and cervical spine radiography were normal. Brain CT showed a right sided parietal skull fracture with an underlying large extradural haematoma causing $7 \mathrm{~mm}$ midline shift. He had a normal full blood count and biochemistry. His arterial blood gases were: $\mathrm{PaO}_{2} 18.4 \mathrm{kPa}$ (on $161 / \mathrm{O}_{2} / \mathrm{min}$ by mask), $\mathrm{PaCO}_{2} 4.5 \mathrm{kPa}$. His wound was covered with a sterile dressing which controlled the bleeding.

PATIENT 2 (PAEDIATRIC OPEN HEAD INJURY)

An 18 month old baby girl was struck on the left side of her head by a falling object. She was found bleeding profusely by her mother. On arrival at the hospital, the child was eye opening to pain, whimpering occasionally, and moving all her limbs to painful stimuli but generally hypotonic. Her pupils were equal and reacting $(5 \mathrm{~mm})$, and when open, she fixed and followed the examiner. She had a $4 \times 6 \mathrm{~cm}$ star shaped dirty wound on the left side of her scalp. There was a visible skul fracture with brain tissue protruding from the wound. She had no other injury. Her vital signs were pulse rate $120 / \mathrm{min}$, blood pressure $90 / 76 \mathrm{~mm} \mathrm{Hg}$, and respiratory rate $26 / \mathrm{min}$. Her temperature was $36.3^{\circ} \mathrm{C}$. She was administered oxygen by mask and intravenous fluids. Her wound was washed with saline and covered with a sterile dressing. Her haemoglobin was $8.7 \mathrm{~g} / \mathrm{dl}$ (haemacrit $27 \%$ ), and the biochemistry was normal. Her arterial blood gases were $\mathrm{pO}_{2} 20.5 \mathrm{kPa}, \mathrm{pCO}_{2} 3.7 \mathrm{kPa}$. Her cervical spine radiograph was normal but her skull radiograph showed a stellate depressed fracture $(2 \mathrm{~mm})$ in her left parietal bone. plement of expert neurosurgical staff on site in each of the units. The survey was completed by two interviewers between noon and $800 \mathrm{pm}$ that day. The distribution of neurosurgical units in Britain and Ireland is shown in the figure.

The on call surgeon was informed that this survey was anonymous and confidential. Having established that he was not dealing with emergency work at that time, the following questions were asked: how many available intensive care beds or high dependency beds were staffed for ventilation of adults and children?; how many free beds for non-

PATIENT 3 (DIFFUSE HEAD INJURY)

A 55 year old woman lost control of her car, which overturned at least once. She seemed not to have been wearing a seat belt and her forehead hit the windscreen. The person in the passenger seat was killed. The ambulance service were at the scene within minutes and found the patient to be unconscious (no eye opening, flexing to pain, and making no sounds but breathing spontaneously). She was intubated in the field, intravenous access was established and she was placed on a spinal board with cervical collar and sand bags. On arrival at the hospital the patient was being ventilated manually with $100 \%$ oxygen. On examination there were good breath sounds on both sides of her chest. Her pulse rate was 86 per minute and her blood pressure was $110 / 80 \mathrm{mmHg}$. She had no eye opening and was flexing to pain. Her pupils were equal and sluggishly reacting. She had bilateral periorbital haematomas. There were bruises over her upper chest but no palpable fractures. Her abdomen was soft and not distended. Peritoneal lavage was negative. Radiographs of her cervical spine, chest, pelvis and thoraco-lumbar spine were normal and she had no limb injuries. Brain CT showed a diffuse type head injury with no mass lesions. The basal cisterns were compressed and the third ventricle not seen. Laboratory tests showed a normal full blood count and biochemistry but abnormal coagulation times (PT 21 seconds, PTTK 42 seconds, and INR 1.2). Her arterial blood gases were: $\mathrm{PaO}_{2} 28.4$ $\mathrm{kPa}, \mathrm{PaCO}_{2} 3.1 \mathrm{kPa}$. The patient was paralysed and sedated and her facial abrasions cleaned. Her medical history was unknown.

For each of the three scenarios the receiving doctor was asked whether the patient would be accepted for transfer. In the first two cases the doctor was asked whether the patient should be intubated and ventilated for transfer and whether the wound should be sutured. In the second case we asked whether the child should have CT before transfer. In all patients advice was sought regarding who should transfer the patient, what blood gases should be aimed for, and whether mannitol, antibiotics, anticonvulsants, or steroids should be given before leaving the emergency department. 
Table 1 Regional populations and bed availability

\begin{tabular}{|c|c|c|c|c|c|c|}
\hline Region & $\begin{array}{l}\text { Population } \\
\text { (millions) * }\end{array}$ & $\begin{array}{l}\text { Adult ITU/HDU } \\
\text { beds empty }\end{array}$ & $\begin{array}{l}\text { Adult ITU/HDU } \\
\text { beds/ million }\end{array}$ & $\begin{array}{l}\text { Paediatric ITU } \\
\text { beds empty }\end{array}$ & $\begin{array}{l}\text { Paediatric ITU } \\
\text { beds/million }\end{array}$ & $\begin{array}{l}\text { Adult ITU/HDU } \\
\text { beds/head injuryt }\end{array}$ \\
\hline East Anglia & 2.4 & 2 & 0.8 & 3 & 1.3 & 1.9 \\
\hline Mersey & 3.0 & 1 & 0.3 & 4 & 1.3 & 0.8 \\
\hline Northern & 3.4 & 1 & 0.3 & 1 & 0.3 & 0.7 \\
\hline North Western & 4.6 & 3 & 0.7 & 3 & 0.7 & 1.5 \\
\hline Oxford & 2.5 & 1 & 0.4 & 1 & 0.4 & 0.9 \\
\hline South West & 3.4 & 3 & 0.9 & 1 & 0.3 & 2.1 \\
\hline Trent & 4.5 & 2 & 0.4 & 2 & 0.4 & 1.0 \\
\hline West Midlands & 6.1 & 3 & 0.5 & 3 & 0.5 & 1.1 \\
\hline Wessex & 2.7 & 0 & 0.0 & 0 & 0.0 & 0.0 \\
\hline Yorkshire & 3.7 & 4 & 0.3 & 1 & 0.3 & 2.5 \\
\hline Wales & 2.3 & 6 & 2.6 & 2 & 0.9 & 6.1 \\
\hline Scotland & 5.4 & 8 & 1.5 & 7 & 1.3 & 3.5 \\
\hline North London & 10.5 & 2 & 0.2 & 0 & 0.0 & 0.4 \\
\hline South London & 7.0 & 1 & 0.1 & 2 & 0.3 & 0.3 \\
\hline Republic of Ireland & 3.6 & 2 & 0.6 & 3 & 0.8 & 1.3 \\
\hline Northern Ireland & 1.6 & 4 & 2.5 & 2 & 1.3 & 5.8 \\
\hline Total & 66.7 & 43 & 0.6 & 35 & 0.5 & 1.5 \\
\hline
\end{tabular}

${ }^{\star}$ These figures are from SBNS Safe Neurosurgery ${ }^{7}$ and because there is regional overlap the overall population from census figures ${ }^{2}$ is actually 63.6 million

†Calculated using number of head injury admissions/year $=313 / 100000,5 \%$ admitted to neurosurgery, adjusted for the regional population.

ventilated emergency admissions were available at that point in time?; how long had the receiving doctor been training as a neurosurgeon and who was supervising him?

The receiving surgeon was then given three hypothetical scenarios of traumatically brain injured patients typical of a referral from a district hospital to a regional neurosurgical unit. The interviewer explained to the neurosurgeon on call that these were to be dealt with as if the interviewer were a general surgical registrar calling from a district accident and emergency department with no neurosurgical services available to him in his own hospital. The three case scenarios are shown in the box.

The time taken from dialling the number of the unit to the time when the neurosurgeon accepted or refused the patient was recorded (the response time). If the surgeon was committed to clinical work he was rung later and times corrected for this delay. If the patient was refused, the time taken to refer the patient to the next nearest neurosurgical unit was calculated and added to the original time until the patient would have been accepted for care.

Populations for each health region were obtained from the 1992 Society of British Neurological Surgeons publication Safe Neurosurgery. ${ }^{7}$ The projected number of head injuries in each region during one 24 hour period were calculated. In the United Kingdom, 313 head injuries/year are admitted to hospital per 100000 population. ${ }^{8}$ Of these 313 patients, a conservative estimate of $5 \%$ might be transferred for neurosurgical care, giving a neurosurgery admission rate of 15.65/100 000 population per year.

\section{Results}

All 36 neurosurgical units in the United Kingdom and Ireland were contacted and included in the study without exception. For the whole of the United Kingdom and Ireland, a population of 63.6 million, ${ }^{23} 43$ adult intensive therapy unit or high dependency unit (HDU) beds were available to ventilate patients with severe head injuries. The regional intensive therapy unit bed availability and the number of projected head injury referrals are given in table 1 . There is overlap of some regions and therefore the total population shown in table 1 is artificially larger than the real population.

In five of the units surveyed, the receiving doctor was a senior house officer, two of whom had registrar as well as consultant cover. In the other 31 units specialist neurosurgical registrars received the referral call. The mean duration of experience was 2.6 (SD 1.73) years at registrar level.

The response time (the time to acceptance for transfer) for the patient with an extradural haematoma was chosen for comparison because the only life saving treatment was urgent operation and the outcome of the operation would be affected by the speed of the response. ${ }^{9}$ The median response time was 6 minutes (range 3-76 minutes; interquartile range 5-11 minutes). Forty two per cent $(n=15)$ of referrals were accepted within 5 minutes of dialling the neurosurgical centre, $72 \% \quad(n=26)$ within 10 minutes, and $89 \%$ $(n=32)$ within half an hour.

Delays greater than 30 minutes in accepting patients occurred in four cases out of the 36 . One occurred because the receiving surgeon was in theatre and therefore unable to come to the phone (33 minutes). The second was caused by a receiving $\mathrm{SHO}$, who was not allowed to accept the case independently and had difficulty consulting with his registrar. The remaining two were both in the London area (50 and 72 minutes) and were caused by refusal due to lack of beds and subsequent referral to other hospitals in the region. There were other units in the country which did not have adult intensive care beds but they were prepared to admit the patient to theatre and retain the patient there postoperatively until the bed shortage was resolved.

Eight of the 36 hospitals refused patient 2 but suggested other units nearby, all of whom accepted the patient. Four of the refusals were on the grounds that the hospital had no paediatric facilities and the paediatric head injury referral centre was nearby in another hospital. The other four were in neurosurgical units with paediatric facilities who ordinarily would have accepted the child but lacked the bed spaces. 
Table 2 Pretransfer therapies advised by neurosurgical units

\begin{tabular}{|c|c|c|c|c|c|}
\hline Patient & $\begin{array}{l}\text { Moderate } \\
\text { hyperventilation } \\
(4-4.5 \mathrm{kPa})\end{array}$ & $\begin{array}{l}\text { Intensive } \\
\text { hyperventilation } \\
(<4 \mathrm{kPa})\end{array}$ & Mannitol & Anticonvulsant & Antibiotics \\
\hline $\begin{array}{l}\text { Patient } 1 \\
\text { Extradural haematoma } \\
(\mathrm{n}=36)\end{array}$ & $14(39 \%)^{\star}$ & $11(31 \%)^{\star}$ & $25(69 \%)$ & $11(31 \%)$ & $3(8 \%)$ \\
\hline $\begin{array}{l}\text { Patient } 2 \\
\text { Paediatric open head injury } \\
(\mathrm{n}=32)\end{array}$ & $5(16 \%) \dagger$ & $6(19 \%) \dagger$ & $1(3 \%)$ & $13(41 \%)$ & $27(84 \%)$ \\
\hline $\begin{array}{l}\text { Patient } 3 \\
\text { Diffuse head injury } \\
(\mathrm{n}=36)\end{array}$ & $15(42 \%)$ & $14(39 \%)$ & $17(47 \%)$ & $2(6 \%)$ & $2(6 \%)$ \\
\hline
\end{tabular}

^Intubation was advised for patient 1 in 35 out of 36 cases (97\%).

tIntubation was advised for patient 2 in 19 out of 32 cases (59\%).

Of the 32 units who had paediatric facilities, eight $(25 \%)$ requested that CT be performed before referral of the infant even if this were to cause a transfer delay.

Patient 3 was refused by six units. Two of these recommended that the patient could be managed in a general intensive care unit without ICP monitoring facilities or neurosurgical intensive care, without higher consultation. The other four refusals were on the grounds that the units had no beds.

Bed status allowing, all 36 units would have accepted patient 1 and all but one receiving neurosurgeon felt that he should be intubated before transfer $(97 \%)$. Nineteen $(59 \%)$ of the 32 units with paediatric facilities requested that patient 2 be intubated before transfer. All units asked for the patient to be accompanied by an anaesthetist except one receiving doctor who recommended that patient 2 could come with a junior doctor or experienced ambulance crew.

All units stated that steroids should not be given to any of the patients. The results of our questions relating to the other therapies are listed in table 2 .

Fifteen units (44\%) requested that we suture the head wound in patient 2 to prevent further blood loss and two receiving surgeons asked for blood to be transfused en route. Six units $(17 \%)$ wished for the 30 year old man with the extradural to have his head wound sutured even though the bleeding was controlled and this would mean delay.

\section{Discussion}

Most head injuries in the United Kingdom (90\%-95\%) are managed without neurosurgical intervention. ${ }^{8}$ Development of neurosurgical expertise within DGHs is not an efficient use of resources as most will deal with only a few severe head injuries in any 1 year. ${ }^{10}{ }^{11}$

Increasing bed numbers combined with a more liberal admission policy can reduce the mortality rate from intracranial haematoma, ${ }^{12}$ but the appropriate management of resources rather than their inadequacy has also to be considered. ${ }^{13-15}$ In 1986, the Royal College of Surgeons working party recommended an additional 100 CT scanners were needed for adequate neurosurgical care. It is now common for district general hospitals to have access to 24 hour CT facilities scanning on site (one third in the south of England in 1991). ${ }^{16}$

With emergency CT in district general hospitals and the specialists based in regional units, guidelines to decide who is to be scanned and who is to be referred to the regional neurosurgical unit are essential for good practice. The most recent guidelines based on a review of the current literature are those issued by the American Brain Trauma Foundation, ${ }^{17}$ The European Brain Injury Consortium, ${ }^{18}$ and The Society of British Neurological Surgeons. ${ }^{19}$ Guidelines for intubation and ventilation have been published by a group of neuroanaesthetists. ${ }^{20}$

Telephone surveys have intrinsic problems, despite the investigators ensuring 100\% participation. Postal surveys can be thought through at the readers' leisure, but it would have not been possible to accumulate the necessary data in such a manner.

The response times to refer patients presented here are more likely to be underestimated because an on call registrar is more likely to accept a hypothetical case than a real one to a unit with stretched resources and the presented information was in an ideal format for decision making. Our projected number of severe head injuries/day is based on data from the early $1980 \mathrm{~s}^{8}$ and we accept that the incidence may well have changed as may the proportion of patients transferred to the neurosurgical unit. Likewise, data on the number of beds available is probably an overestimate because on a countrywide scale, the day before the SBNS conference is the quietest time of year from an elective surgery reducing the burden on the local intensive therapy unit. With traumatic brain injury making up only part of emergency neurosurgical practice, 43 beds available nationally to cope with the projected 28.6 head injuries is far from sufficient especially if the number of beds are likely to be overestimated.

Five out of the eight London hospitals had no adult intensive therapy unit beds available and the other three had one each, in a region of over 17 million and a projected seven referrals of severe head injury/day. It is clear that on the day we performed our study there was a critical intensive therapy unit bed shortage in south east England, particularly as neighbouring Wessex also had no beds available for admission.

Delay in the evacuation of extradural haematoma is associated with increased morbidity and mortality. ${ }^{91}$ It is difficult to quantify the increases in risk with delay but it has been suggested that a delay from diagnosis to evacuation of greater than 2 hours is unacceptable. ${ }^{9} \mathrm{~A}$ 
refusal of patient 1 by a neurosurgical unit or a delay in acceptance would have a significant effect on outcome.

In five units the on call person had no previous experience of neurosurgery and one unit had a preregistration house officer who could not be more than 3 months qualified as a doctor considering the time of year we did this study. Nevertheless, this did not cause any undue delay in referral in the case of that unit as the registrar was nearby. One of the effects of the hours of work restrictions are that not all neurosurgical units can be staffed with a specialist registrar receiving emergency calls.

Consensus recommendations for patients with severe head injury who are in coma are that they should be transferred as rapidly as possible after being fully resuscitated and stabilised for neurosurgical intensive care. ${ }^{40-24}$ They should be accompanied by an anaesthetist or a doctor who is adept at handling ventilated patients ${ }^{16}$ as recommended by all the neurosurgical units in this study. Intensive hyperventilation $\left(\mathrm{PaCO}_{2}<4 \mathrm{kPa}\right)$ was advocated by almost a third of surgeons for patients 1 and 3, despite published guidelines. ${ }^{20}$ Three surgeons (all specialist registrars) advised keeping the $\mathrm{PaCO}_{2}$ below $3.5 \mathrm{kPa}$.

Mannitol is used in the emergency treatment of patients with head injury who are in danger of brain herniation as a result of raised intracranial pressure provided blood volume is maintained by adequate fluid replacement. Such diuresis can cause dehydration and hypotension ${ }^{5}$ and therefore should be avoided in a patient with hypotension or severe blood loss. In the case of the child with the open head injury (and therefore self decompressing) there was no evidence of raised intracranial pressure. Additionally, she had clearly had moderate blood loss, important in a child that age. One neurosurgical unit advised that mannitol be given to this child before transfer.

There is class I data (randomised, controlled, prospective studies) that shows there is no evidence of benefit of steroids in acute head injury. ${ }^{25}$ This is generally known among neurosurgical trainees as shown by the unanimous advice.

Prophylactic use of anticonvulsant drugs is not recommended in general but the American group suggest it as an option for those at high risk of seizures (for example an open head injury where the dura is not intact).$^{2126}$ They reduce the incidence of early but not late posttraumatic seizures and therefore they should only be used as prophylaxis in the early postinjury period. ${ }^{26}{ }^{27}$ It would therefore follow that patients 1 and 3 would not benefit from prophylaxis but patient 2 would. More interviewees recommended antiepileptics for patient 2 than the others but there was no obvious consensus on this matter.

As with anticonvulsants it is not clear that there is benefit of antibiotic prophylaxis in head injuries except in patients with compound, depressed skull fractures or penetrating head wounds. ${ }^{27}$ There is an argument for giving antibiotics to patient 2 as $84 \%$ of doctors advised. There is absolutely no argument for giving antibiotics to patient 3 , who had some scratches on her face and no evidence of aspiration or CSF leak. However, two receiving units recommended antibiotics.

Patient 3 presented a conundrum on two levels. Firstly, some units would not accept a patient of this sort, as there are some neurosurgeons who do not advise neurosurgical intensive care for diffuse head injuries on the grounds that they will not need an operation and can be cared for within a general intensive therapy unit without intracranial pressure monitoring. Secondly, although she had a normal supine chest radiograph and no evidence of rib fracture she was at risk of having a major thoracic injury (for example, aortic dissection) which can present late. ${ }^{28}$ Only $16(44 \%)$ of the 36 units actually had a thoracic facility on site.

Our findings show that there are large differences in the availability of neurosurgical intensive unit beds between regions and the shortage in the London area is most acute. There were also wide differences in treatment and acceptance protocols for severe head injuries throughout neurosurgical units and some of the advice given would not be in line with published guidelines.

1 Cairns HWB, Jefferson G, Dott N, et al. Notes on the neurosurgical needs of the population and the training of the neurosurgeon. Report from The Planning Committee of the Society of British Neurological Surgeons 1945-47. Manchester: Hotspur Press, 1947.

2 Population and Vital Statistics for the United Kingdom. Population Estimates Unit. Office of National Statistics. Crown Copyright, 1994.

3 Census of Population of, Ireland, 1996. Vol 1. An PhríomhCensus of Population of Ireland, 1996.
Oifig Staidrimh na h-Eireann, 1996.

4 Miller JD. Head injury. F Neurol Neurosurg Psychiatry 1993; 56:440-7.

5 Pickard JD, Czosnya M. Management of raised intracranial pressure. $\mathcal{F}$ Neurol Neurosurg Psychiatry 1993;56:845-58.

6 Kirkpatrick PJ, Czosnyka M, Pickard JD. Multimodal monitoring in neurointensive care. $\mathcal{F}$ Neurol Neurosurg Psychiatry 1996;60:131-9.

7 Society of British Neurological Surgeons. Safe neurosurgery. The maintenance and development of high standards. London: SBNS, February 1993

8 Jennett B, MacMillan R. Epidemiology of head injury. BMF 1981;282:101-4.

9 Mendelow AD, Karmi MZ, Paul KS, et al. Extradural haematoma: effect of delayed treatment. BMF 1979;i: $1240-2$.

10 Royal College of Surgeons of England. Report of the working party on head injuries. London: Royal College of Surgeons, 1986

11 Marsh H, Maurice-Williams RS, Hatfield R. Closed head injuries: where does delay occur in the process of transfer to neurosurgical care? Br f Neurosurg 1989;3:13-20.

12 Teasdale G, Galbraith S, Murray L, et al. Management of traumatic intracranial haematoma. BMF 1982;285:1695-7.

13 Brocklehurst G, Gooding M, James G. Comprehensive care of patients with head injuries. BMF 1987;294:345-7.

4 Bryden JS, Jennett B. Neurosurgical resources and transfer policies for head injuries. BMF 1983;286:1791-3.

15 Suggestions from a group of neurosurgeons. Guidelines for initial management after head injury in adults. BMF 1984; 288:983-5.

16 Vyvyan HAL, Kee S, Bristow A. A survey of secondary Vyvyan HAL, Kee S, Bristow A. A survey of secondary
transfers of head injured patients in the south of England. Anaesthesia 1991;46:728-31.

17 Anonymous. Guidelines for the management of severe head injury. Brain Trauma Foundation, American Association of Neurological Surgeons, Joint Section on Neurotrauma and Critical Care. Fournal of Neurotrauma' 1996;13:641-734.

18 Maas AI, Dearden M, Teasdale GM, et al. EBIC-guidelines for management of severe head injury in adults. European Brain Injury Consortium. Acta Neurochirurgica 1997;139: 286-94.

19 Bartlett J, Kett-White R, Mendelow AD, et al. Recommendations from the Society of British Neurological Surgeons. Br $\mathcal{F}$ Neurosurg 1988;12:349-52.

20 Gentleman D, Dearden M, Midgeley S, et al. Guidelines for the resuscitation and transfer of patients with severe head injury. BMF 1993;307:547-52.

21 Jeffreys RV, Jones JJ. Avoidable factors contributing to the death of head injury patients in general hospitals in Mersey death of head injury patients in
region. Lancet 1981;ii:459-61.

22 Gentleman D, Jennett B. Hazards of inter-hospital transfer of comatose head injured patients. Lancet 1981;ii:853-5. 
23 Gentleman D. Preventing secondary brain damage after head injury: a multidisciplinary challenge. Injury 1990;21

24 Lambert SM, Willett K. Transfer of multiply injured patients for neurosurgical opinion: a study of the adequacy of assessment and resuscitation. Injury 1993;24:333-6.

25 Kirkpatrick PJ. On guidelines for the management of severe head injury [editorial]. I Neurol Neurosurg Psychiatry 1997; 62:109-11.
26 Anonymous. The role of antiseizure prophylaxis following head injury. Brain Trauma Foundation. I Neurotrauma 1996;13:731-4

27 Dunn LT, Foy PM. Anticonvulsant and antibiotic prophylaxis in head injury. Ann R Coll Surg Engl 1994;76:353-4.

28 American College of Surgeons Committee on Trauma. ATLS course manual. Chicago: American College of Surgeons, 1993.

\section{HISTORICAL NOTE}

\section{Arnold Chiari, or "Cruveilhier Cleland Chiari" malformation}

In 1891, Hans Chiari (1851-1916) wrote his first paper on ectopia of cerebellar tissue. ${ }^{1} \mathrm{He}$ described a malformation of the cerebellum and brainstem with varying descent through the foramen magnum into the cervical canal. He related the changes to congenital hydrocephalus, because he had not observed the deformities in late onset or acute hydrocephalus. The malformation is not described in Kinnier Wilson's Neurology, and presumably was long regarded as a rare curiosity until the surgery of dysraphism and hydrocephalus began. Unfortunately, some English translations of Chiari's work ${ }^{2}$ contained inaccuracies, but Koehler has corrected these. Chiari described three grades:

Type 1 showed "elongation of the tonsils and medial parts of the inferior lobes of the cerebellum into cone shaped projections, which accompany the medulla oblongata into the spinal canal."

In most cases the cerebellum itself appeared normal, but in some instances there was softening or sclerosis. The fourth ventricle was normal or slightly elongated; the medulla appeared flattened. Chiari was uncertain whether these changes cause symptoms or not, but he was inclined to believe bulbar symptoms might result.

He recorded type 2 changes in a 6 month old child who had paraplegia, a paralysed bladder, and had succumbed to pneumonia. The pons descended into the spinal canal over $6 \mathrm{~mm}$. And the medulla extended to the third cervical vertebra. The baby had hydrocephalus and "a cylindrical hole $6 \mathrm{~mm}$ in width, filled with clear serum" in the dorsal side of the spinal cord extending from the first to the seventh segment. A second cavity, a "hydromyelie" was found a few segments below.

There was also diastematomyelia, meningomyelocoele, and displacement of the conus to the level of the sacrum.

He found only one example of type 3, a malformation with absence of part of the tentorium cerebelli and prolapse of the cerebellum and fourth ventricle into the cervical canal and an associated hydromyelic cavity in communication with the fourth ventricle.

In 1896, Chiari added 63 cases of congenital hydrocephalus of which 14 children or adults had a type 1 malformation, seven had a type 2-mainly neonates a few days old, who had varying types of spinal dysraphism. He had noticed that the severity of the hydrocephalus did not relate to the extent of the malformation and he postulated that defective growth of the skull caused raised local pressure, presumably forcing down the hindbrain. He thought that there was a graded increase, ranging from descen of cerebellar tissue within the fourth ventricle, to descent with, but dorsal to it. He also recorded two instances of hypoplasia of the cerebellum that he believed had been caused by hydrocephalus.

Hans Chiari was the son of a famous Austrian gynaecologist, JBVL Chiari, who held chairs in Prague and Vienna and described post-partum galactorrhoea with pituitary adenoma, amenorrhoea, and low follicle stimulating hormone (Chiari-Frommel syndrome), which we would now recognise as prolactinoma. Hans was professor of pathology in Prague's German University and late in Strasbourg. He wrote a classical history of pathology and the first account of chorionic carcinoma. His vast knowledge was widely admired, but if irritated by poor preparation of tissue sections by his students, he was said to rap their knuckles. He wrote extensively on topics including the pancreas and its capacity for autodigestion, and endarteritis chronica deformans of the carotid bifurcation with cerebral embolism. He died suddenly after throat infection

Chiari gave credit to other writers including Arnold and Cleland. John Cleland of Edinburgh (1835-1925) wrote a brief account in 1883, and his illustrations were no distinct. He described an infant with spina bifida and hydrocephalus with the cerebella nodulus displaced into an elongated fourth ventricle, separating the cerebellar lobes. This corresponded to Chiari's type $2 .^{5}$ Much of his paper was devoted to encephalocoele and spina bifida.

However, more than 50 years earlier, Jean Cruveilhier (1791-1874), physician, and Professor of Anatomy in Paris, in his two volume atlas $^{6}$ clearly described and illustrated ${ }^{\star}$ many examples of spina bifida and hydrocephalus, usually with infection of the sac and meningitis. In a second case of meningomyelocoele he described the "Arnold-Chiari malformation" with diastematomyelia ( $\mathrm{p} 2$ )

" . . the spinal cord is divided into two perfectly distinct lateral cords; each cord giving off nerves with their double roots . . the upper part of the considerably dilated cervical region, contained both the medulla oblongata and the corresponding part of the cerebellum which was elongated and covered the fourth ventricle, itself enlarged and elongated."

He mentioned two other cases of hindbrain malformation observed by a $M$ Sestier.

Julius Arnold (1835-1915) was a pupil of Virchow and Friedreich and became Professor of Anatomy at Heidelberg. His paper in 1894 was about an infant with spina bifida, but without hydrocephalus. Chiari believed that it was an example of his type 2 cases, despite the absence of enlarged ventricles. The attachment of Arnold's name is probably inappropriate since his writings were mainly about the dysraphism; and, consideration of the hindbrain descent was a small and peripheral issue.

Modern authorities regard type 1 as an ectopia of the tonsils, sometimes with minor deformity of the medulla into the foramen magnum. Type 2 is almost always accompanied by hydrocephalus and a myelomeningocoele; it includes lengthening of the vermis and tonsils and in some case the elongated fourth ventricle and their displacement below the foramen magnum. The dorsal part of the medulla is shifted caudally and overrides the cord in a Z-shaped kink impacted in the tight foramen; the posterior fossa is often broad and shallow and the tentorium may be rudimentary and low; hydromyelia, syringomyelia, and a split cord are frequent. Type 3 is a cervical spina bifida, the entire cerebellum herniated through the foramen magnum forming a myelocerebellomeningocoele. Type 4 is cerebellar hypoplasia. Chiari's classification is still widely accepted by neuropathologists.

J M S PEARCE 304 Beverley Road, Anlaby, Hull HU10 7BG, $U K$

1 Chiari H. Ueber Veränderungen des Kleinhirns infolge von Hydrocephalie des Grosshirns. Dtsch Med Wochenschr 1891;17:1172-5.

2 Wilkins RH, Brody IA. The Arnold-Chiari malformation. Neurological classics 38. Arch Neurol 1971;25:376-9.

3 Koehler PJ. Chiari's description of cerebellar ectopy (1891). F Neurosurg 1991;75:823-6.

4 Chiari H. Uber Veränderungen des Kleinhirns, des Pons und der Medulla Oblongata infolge von congenitaler Hydrocephalie des Grosshirns. Denkschr der Kais Akad Wiss Wien mathnaturw 1896;63:71-116.

5 Cleland J. Contributions to the study of spina bifida, encephalocoele, and anencephalus. $\mathcal{F}$ Anat Pysiol (London) 1883;17:257-91.

6 Cruveilhier J. L'Anatomie pathologique du corps humain;descriptions avec figures lithographiées et coloriees; diverses alterations morbides don't le corps humain et susceptible. 2 Vols. Paris: Bailliere, $1829-42$

7 Larroche JC. In: Adams JH, Corsellis JAN, Duchen LW, eds. Greenfield's neuropathology, 4th ed. London: Arnold 1984:393-5. 